\title{
Persistent Vegetative State after Diabetic Ketoacidosis Triggered by an Overdose of Psychotropic Agents
}

\author{
Takeshi Kawashita, Mikio Nakajima, Richard H. Kaszynski, Masamitsu Shirokawa, \\ Tomotsugu Nakano, Koji Ochiai, Yoshitaka Inoue and Hideaki Goto
}

\begin{abstract}
:
A 28-year-old man with type 1 diabetes mellitus was admitted for shock and coma due to diabetic ketoacidosis. Despite aggressive treatment and management of the patient's underlying clinical issues, the patient remained in a comatose state. Further investigations revealed an excess consumption of psychotropic agents; however, there was no evidence of an insulin overdose. Physicians should be aware that, in patients who are highly dependent upon insulin, an overdose of psychotropic agents can lead to hypoxic-ischemic brain injury.
\end{abstract}

Key words: diabetic ketoacidosis, hypoglycemia, hypoxic-ischemic brain injury, drug overdose, persistent vegetative state

(Intern Med 58: 247-250, 2019)

(DOI: 10.2169/internalmedicine.1041-18)

\section{Introduction}

Diabetic ketoacidosis (DKA) is a serious life-threatening acute complication associated with diabetes mellitus (DM) and is caused by the absolute or relative depletion of insulin, which leads to severe hyperglycemia and ketoacidosis. Changes in the mental status usually occur in the acute phase of DKA; however, it can become a persistent clinical feature in an isolated fraction of cases. Some have reported that cerebral edema with poor neurological outcomes can be a complication of DKA in pediatric patients (1).

We herein report a case of DKA triggered by an overdose of psychotropic agents in an adult patient who proceeded into a persistent vegetative state (2), most likely as a result of underlying hypoxic-ischemic brain injury. The present case report serves as a reminder that, under certain conditions, DKA patients are at a higher risk of developing a persistent vegetative state.

\section{Case Report}

A 28-year-old man diagnosed with type $1 \mathrm{DM}$ at 3 years of age was discovered in his house lying unconscious on his back. He was in a comatose state and was admitted to our emergency department. Three days prior to admission, the patient had been confirmed to be in a healthy state by his family; however, his family recalled the patient contemplating notions of suicide. He had never been diagnosed or treated for any psychological disorders and did not have a family history of DM. He had been treated with 24 units of insulin degludec and 7-8 units of insulin aspart in the morning, 6-8 units of insulin aspart at midday, and 13-15 units of insulin aspart in the evening.

On arrival, the patient was in deep comatose state, with a Glasgow Coma Scale (GCS) of E1V1M1. His body temperature was $36.0^{\circ} \mathrm{C}$, blood pressure unmeasurable, heart rate 154 beats/min, and oxygen saturation $\left(\mathrm{SpO}_{2}\right) 79 \%$ at 10 $\mathrm{L} /$ min supplemental oxygen. On a physical examination, the patient presented with a Kussmaul breathing pattern, and his pupils measured $2.5 \mathrm{~mm}$ bilaterally and were non-reactive to light. The remains of what appeared to be an admixture of gastric fluid/contents were found in varying amounts along the neck and face, suggesting frequent preceding episodes of nausea and vomiting. In his comatose state, the patient clamped his tongue with his jaws, resulting in discoloration

Emergency and Critical Care Center, Tokyo Metropolitan Hiroo Hospital, Japan

Received: February 17, 2018; Accepted: July 2, 2018; Advance Publication by J-STAGE: September 12, 2018

Correspondence to Dr. Takeshi Kawashita, m09034tk@jichi.ac.jp 
Table. Laboratory Data on Admission.

\begin{tabular}{|c|c|c|c|}
\hline \multicolumn{2}{|c|}{ Complete blood cell count } & \multicolumn{2}{|c|}{ Arterial blood gas analysis $\left(\mathrm{O}_{2}\right.$ at $\left.10 \mathrm{~L} / \mathrm{min}\right)$} \\
\hline White blood cells & $13,800 / \mu \mathrm{L}$ & $\mathrm{pH}$ & 7.155 \\
\hline Hemoglobin & $19.0 \mathrm{~g} / \mathrm{dL}$ & $\mathrm{PaO}_{2}$ & $79.3 \mathrm{mmHg}$ \\
\hline Hematocrit & $56.0 \%$ & $\mathrm{PaCO}_{2}$ & $24.4 \mathrm{mmHg}$ \\
\hline \multirow[t]{2}{*}{ Platelets } & $30.7 \times 10^{4} / \mu \mathrm{L}$ & $\mathrm{HCO}_{3}^{-}$ & $8.4 \mathrm{mmol} / \mathrm{L}$ \\
\hline & & Base excess & $-18.2 \mathrm{mmol} / \mathrm{L}$ \\
\hline \multicolumn{2}{|c|}{ Biochemical examination } & Lactate $^{\ddagger}$ & $5.25 \mathrm{mmol} / \mathrm{L}$ \\
\hline Sodium & $145 \mathrm{mmol} / \mathrm{L}$ & & \\
\hline Potassium & $5.8 \mathrm{mmol} / \mathrm{L}$ & Urinalysis & \\
\hline Chloride & $108 \mathrm{mmol} / \mathrm{L}$ & Protein & $(3+)$ \\
\hline Calcium & $10.2 \mathrm{mg} / \mathrm{dL}$ & Glucose & $(3+)$ \\
\hline Urea nitrogen & $54.4 \mathrm{mg} / \mathrm{dL}$ & Ketone bodies & $(3+)$ \\
\hline Creatinine & $1.15 \mathrm{mg} / \mathrm{dL}$ & & \\
\hline Total bilirubin & $1.7 \mathrm{mg} / \mathrm{dL}$ & & \\
\hline Creatinine kinase & $2,298 \mathrm{U} / \mathrm{L}$ & & \\
\hline LDH & $357 \mathrm{U} / \mathrm{L}$ & & \\
\hline AST & $19 \mathrm{U} / \mathrm{L}$ & & \\
\hline ALT & $14 \mathrm{U} / \mathrm{L}$ & & \\
\hline ALP & $223 \mathrm{U} / \mathrm{L}$ & & \\
\hline Total protein & $8.6 \mathrm{~g} / \mathrm{dL}$ & & \\
\hline Albumin & $4.5 \mathrm{~g} / \mathrm{dL}$ & & \\
\hline CRP & $17.39 \mathrm{mg} / \mathrm{dL}$ & & \\
\hline Glucose & $465 \mathrm{mg} / \mathrm{dL}$ & & \\
\hline $\mathrm{HbA1c}(\mathrm{NGSP})^{\dagger}$ & $7.6 \%$ & & \\
\hline
\end{tabular}

and swelling that ultimately obstructed the patient's airway. He had a sacral decubitus ulcer measuring approximately 7 $\mathrm{cm} \times 7 \mathrm{~cm}$.

Laboratory tests showed metabolic acidosis, hemoconcentration, leukocytosis, elevated C-reactive protein levels, hyperglycemia $(350 \mathrm{mg} / \mathrm{dL})$, hypernatremia, hyperkalemia, renal dysfunction, and rhabdomyolysis (Table). Urine glucose and ketone levels were high as measured via Tes-Tape ${ }^{\circledR}$. Chest X-ray and computed tomography (CT) showed a consolidation in the lower-left lobe, which was likely due to chemical aspiration from vomiting. Triage ${ }^{\circledR}$ Drugs of Abuse Panel (Sysmex, Kobe, Japan) and head CT showed no significant findings (Fig. 1).

With a diagnosis of DKA, fluid resuscitation and continuous intravenous insulin infusion were initiated. After infusion of the initial $1,000 \mathrm{~mL}$ of extracellular fluid, the patient's blood pressure improved to $100 / 60 \mathrm{mmHg}$. Tracheal intubation and mechanical ventilation were warranted due to the patient's compromised mental status and respiratory failure. Shortly after intubation, the patient's $\mathrm{SpO}_{2}$ levels improved significantly. Glucose management was initiated with a target serum glucose level of $200 \mathrm{mg} / \mathrm{dL}$. Despite the clinical correction of hypoxia, hypovolemia, hyperglycemia, renal dysfunction, infection, and electrolyte disorder, his altered mental status persisted.

An electroencephalogram on day 5 revealed generalized slow waves. Magnetic resonance imaging (MRI) of the brain with diffusion-weighted imaging and fluid-attenuated inversion recovery on the same day revealed hyperintensities in the bilateral basal ganglia but none in the thalamus, brainstem, or cerebellum. Other hyperintense regions were partially observed in the cortical layers (Fig. 2).

Subsequent cursory observations of the patient's home by family members suggested that the patient had ingested 8 tablets of $25 \mathrm{mg}$ diphenhydramine and 12 tablets of $5 \mathrm{mg}$ clotiazepam, in what was most likely an attempted suicide. His insulin injectors were nearly full, and there was no evidence to suggest an insulin overdose. At its peak throughout the clinical course, the patient's mental status improved to a GCS of E3V1M4. The patient was subsequently transferred to a convalescent hospital on the 143rd hospital day.

\section{Discussion}

Although rarely a persistent issue, disturbances in mental status are a frequent clinical feature of patients with DKA. We experienced a unique case in which the patient developed a persistent vegetative state (2) subsequent to DKA. Based upon the patient's clinical findings, the primary etiology of his status was attributed to hypoxic-ischemic brain injury due to airway obstruction caused by vomiting and suppression of breathing. His $\mathrm{SpO}_{2}$ on arrival was low despite being placed on highly concentrated oxygen supplementation. The presence of a sacral decubitus ulcer and 

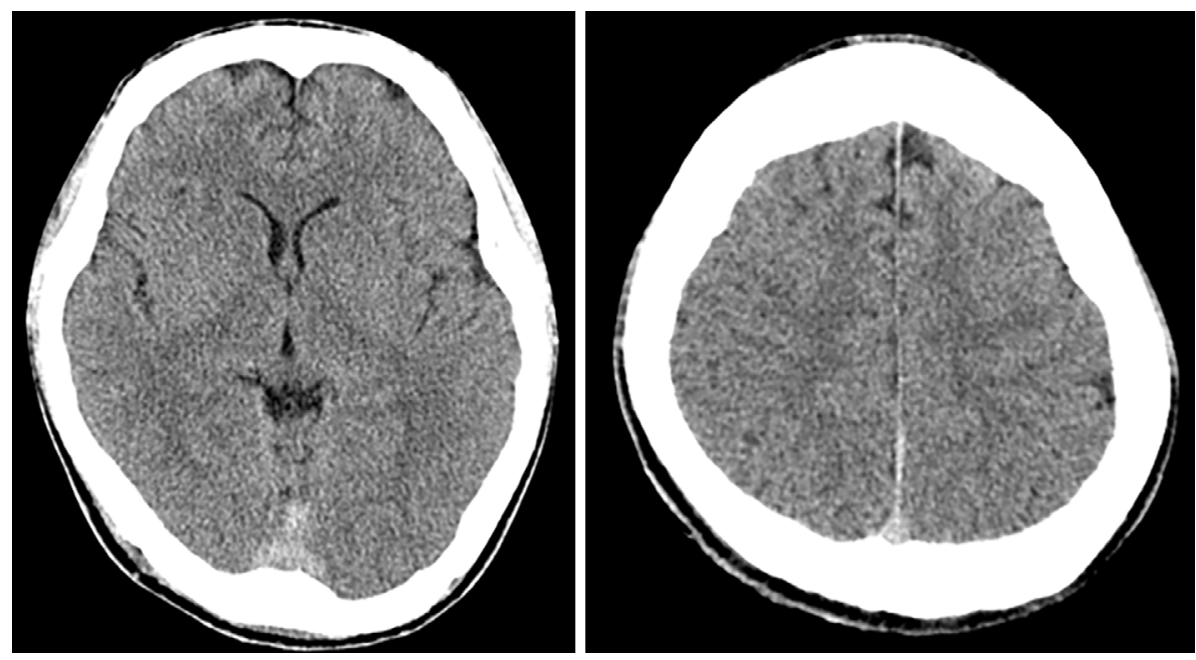

Figure 1. Head computed tomography findings on admission. There were no significant findings.
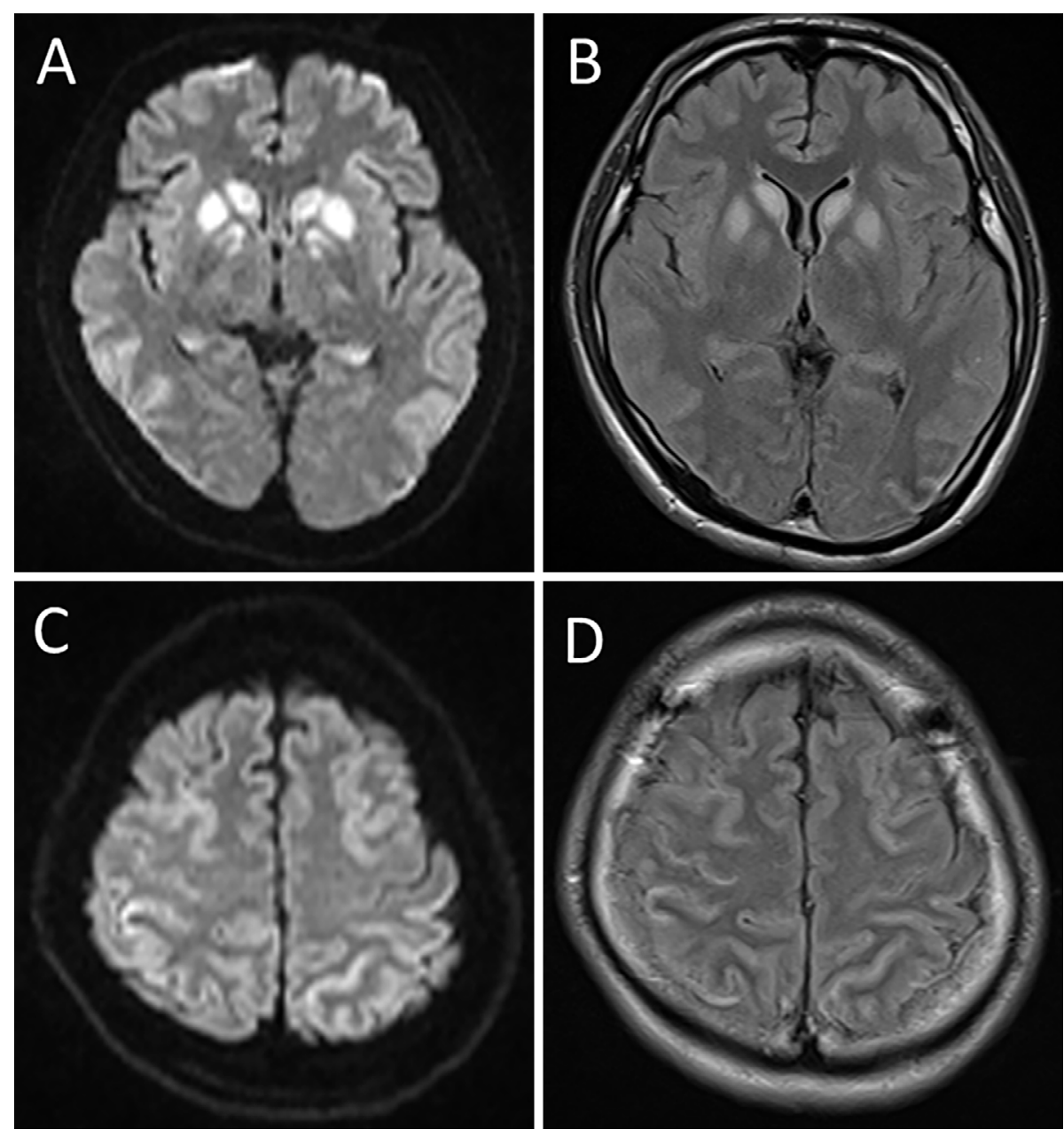

Figure 2. Head magnetic resonance imaging on day 5. Hyperintensity in the bilateral basal ganglia was seen on (A) diffusion-weighted imaging and (B) fluid-attenuated inversion recovery. A hyperintense area was partially seen on the cortical layers on (C) diffusion-weighted imaging and (D) fluidattenuated inversion recovery.

rhabdomyolysis suggested that the patient had been unconscious in the supine position for an undetermined yet extended period of time. In addition, the ensuing hypovolemic shock from DKA likely aggravated the impaired oxygen de- livery. High-intensity changes noted in the bilateral basal ganglia on T1-weighted imaging, as in this case, are associated with a poor neurological prognosis (3).

$\mathrm{He}$ ingested $3.08 \mathrm{~kg} / \mathrm{mg}$ of diphenhydramine and 0.92 
$\mathrm{mg} / \mathrm{kg}$ of clotiazepam. This equates to a dosage equivalent to $41.9 \%$ of the lowest published human lethal dose of diphenhydramine $(7.35 \mathrm{mg} / \mathrm{kg})(4), 0.79 \%$ and $0.06 \%$ of the oral median lethal dose of diphenhydramine (390 mg/kg) (5) and clotiazepam $(1,461 \mathrm{mg} / \mathrm{kg})(6)$ in rats, respectively. No reports were available regarding the lowest published oral lethal dosage of clotiazepam in humans. We determined that neither of the drugs were within the lethal range; however, an overdose of diphenhydramine frequently causes nausea and vomiting, and clotiazepam holds the potential to suppress breathing. In addition, diphenhydramine exerts synergetic effects with central nervous system depressants. Therefore, these drugs may have contributed to the acceleration and exacerbation of the airway obstruction and respiratory suppression. In patients with ketoacidosis, hyperventilation usually occurs to compensate for the underlying metabolic acidosis. Patients with an overdose of psychotropic agents demonstrate a lack of respiratory compensation as a result of the drugs' natural tendencies to suppress ventilation, making these patients susceptible to pulmonary acidosis.

Given the consistency of the brain MRI findings, hypoglycemic encephalopathy is another differential diagnosis to consider with regard to the cause of the persistent vegetative state described in this case (7-9). Although there was no trace of insulin overdose, the patient could have developed hypoglycemia if he had ingested the psychotropic agent subsequent to delivering a normal dosage of insulin. While prognostic studies on hypoglycemic encephalopathy are limited, one study reported that irreversible central nervous system damage occurred more frequently when the hypoglycemic status was maintained for a period exceeding 60 $\min (10)$.

In this patient, disturbance of consciousness from an overdose of psychotropic agents may have led to an inability to self-medicate using insulin and subsequent DKA. The dehydration caused by the DKA likely delayed the excretion and clearance of the psychotropic agents and prolonged their sedative effects. Even when the effects of the psychotropic agents have dissipated, the simultaneous development of DKA resulted in the persistent disturbance of consciousness. Furthermore, vomiting, which is a hallmark of DKA $(11,12)$, most likely led to aspiration pneumonia, airway obstruction, and hypoxia in this patient.
We encountered a case of a persistent vegetative state in a patient with DKA compounded by a suicide attempt using psychotropic agents. Failure to administer insulin in type 1 DM patients causes DKA. Physicians should be aware that, in type 1 or type $2 \mathrm{DM}$ patients who are highly dependent on insulin, an overdose of psychotropic agents can increase the risk of developing hypoxic-ischemic brain injury.

The authors state that they have no Conflict of Interest (COI).

\section{References}

1. Wolfsdorf J, Glaser N, Sperling MA. Diabetic ketoacidosis in infants, children, and adolescents: a consensus statement from the American Diabetes Association. Diabetes Care 29: 1150-1159, 2006.

2. Multi-Society Task Force on PVS. Medical aspects of the persistent vegetative state (2). N Engl J Med 330: 1572-1579, 1994.

3. Nogami K, Fujii M, Kato S, et al. Analysis of magnetic resonance imaging (MRI) morphometry and cerebral blood flow in patients with hypoxic-ischemic encephalopathy. J Clin Neurosci 11: 376380, 2004.

4. Arena JM: Poisoning; Toxicology, Symptoms, Treatments. 2nd ed. Thomas, Springfield, 1970: 73.

5. Russ Pharmacol Toxicol. Euromed Publications, London, 40: 42, 1977.

6. Drugs in Japan. 6th ed. Jiho, Tokyo, 1982: 233 (in Japanese).

7. Kang EG, Jeon SJ, Choi SS, et al. Diffusion MR imaging of hypoglycemic encephalopathy. AJNR Am J Neuroradiol 31: 559-564, 2010.

8. Kuriyama A, Sato K. Hypoglycemic encephalopathy. CMAJ 187: E437, 2015.

9. Ma JH, Kim YJ, Yoo WJ, et al. MR imaging of hypoglycemic encephalopathy: lesion distribution and prognosis prediction by diffusion-weighted imaging. Neuroradiology 51: 641-649, 2009.

10. Sakel M. The methodical use of hypoglycemia in the treatment of psychoses. 1937. Am J Psychiatry 151: 240-247, 1994.

11. Matz R. Hypothermia in diabetic acidosis. Hormones 3: 36-41, 1972.

12. Imagawa $A$, Hanafusa $T$, Uchigata $Y$, et al. Fulminant type 1 diabetes: a nationwide survey in Japan. Diabetes Care 26: 2345-2352, 2003.

The Internal Medicine is an Open Access journal distributed under the Creative Commons Attribution-NonCommercial-NoDerivatives 4.0 International License. To view the details of this license, please visit (https://creativecommons.org/licenses/ by-nc-nd/4.0/).

(C) 2019 The Japanese Society of Internal Medicine Intern Med 58: 247-250, 2019 